\title{
UM NOVO BLENNIIDAE DO LITORAL DE SÃO PAULO, BRASIL (ACTINOPTERYGII - PERCIFORMES)
}

Sérgio Ypiranga Pinto*

Quando da triagem do material que nos foi cedido pelo Instituto Oceanográfico da Universidade de São Paulo, verificamos a existência de um exemplar da família Blenniidae ainda não assinalado na literatura; tal circunstância nos levou a criar uma nova espécie, a qual dedicamos ao ilustre cientista daquela Instituição, Dr. João de Paiva Carvalho, a quem estimamos e somos gratos pela sua colaboração. Agradecemos ao Conselho Nacional de Pesquisas pela bôlsa que nos foi concedida.

Não nos foi possível proceder estudos sôbre a morfologia interna em virtude de só possuirmos um único exemplar desta espécie.

Blennius paivai sp.nov.

HoLóTIPo - M.N.I. 9119, macho.

LOCALIDADE-TIPo - Rio Nóbrega, abaixo do local do cêrco experimental, Cananéia, São Paulo, Brasil.

ASPECTO GERAL (Fig. 1) - Blenídeo frágil, de corpo fusiforme, totalmente desprovido de escamas. Perfil dorsal retilíneo fazendo um ângulo abrupto com o focinho; bôca anterior, olhos medíocres, membrana branquiostegal livre e ampla abertura branquial. Numerosos poros localizados na cabeça; cirros nas regiões supra-orbital e nasal; perfil ventral reto, arqueando-se ao atingir a região gular. Linha lateral composta por poucos poros e arqueada anteriormente.

* Museu Nacional - Rio de Janeiro, DF. 
COLORAÇÃo (em álcool) - Fraco amarelo-palha mascarado por intensa pigmentação negra que dá ao conjunto um aspecto denegrido quase que totalmente. $O$ ventre, base da caudal, pedúnculo e parte inferior da membrana branquiostegal com maior predominância do tom amarelo. Maior incidência de pigmentação sôbre os raios das nadadeiras e branquiostegais. Não nos é possível assinalar maculações no exemplar.

CABEÇA (Fig. 2) - De aspecto globoso e revestida por tegumento, apresenta a sua porção anterior formando um ângulo de cêrca de 140 graus com o perfil dorsal. A bôca, de abertura média, localiza-se em posição anterior e ligeiramente voltada para baixo, tendo os lábios bem desenvolvidos, principalmente, o superior e apresentando acentuados sulcos que se interrompem à altura da sínfise mediana; ocorre um segundo sulco, menor, encimando aquêle do lábio superior.

As narinas são duplas, havendo entre as componentes de cada par distâncias aproximadamente iguais; o primeiro par possui uma prega dérmica tubular, em cujo bordo superior acha-se um único cirro de comprimento igual ao diâmetro vertical das narinas do segundo par, que estão localizadas próximo à margem anterior das órbitas e apresentam maior abertura que as precedentes. Os olhos são pequenos, aproximadamente circulares, situados no vértice do ângulo perfil dorsal-perfil anterior da cabeça e portam na região supra-orbital um único tentáculo de comprimento igual ao diâmetro ocular; êsse tentáculo tem o aspecto de uma pirâmide de base quadrada, cujos ângulos diedros sofreram diminuição e as faces laterais tornaram-se côncavas. Note-se, ainda, que a aresta voltada para a porção posterior da órbita se interrompe no têrço superior não atingindo o tôpo da pirâmide (Figs. 6 e 7). As faces são salientes, ficando bem marcado o ramo ascendente do pré-opercular, verifica-se aí o ponto de largura máxima do indivíduo. Os poros, abundantes, situam-se em fileiras acompanhando o desenvolver do pré-opercular (5), o ramo e bordo inferiores do dentário (4) e bordo posterior da órbita (6) ; em tôrno das narinas do primeiro par existem quatro poros dispostos em forma de cruz; sôbre a fontanela, pouco acima da linha que une as narinas do segundo par, um ao lado do outro e com um diminuto afastamento entre si, há dois poros; sôbre o espaço interorbital há dois poros, um atrás do outro. Finalmente encontramos, ao início da linha lateral, um grupo de quatro poros dispostos em $Y$, cujo ramo vertical se orienta anteroposteriormente (Figs. 3 e 4). Os raios branquiostegais sĩo nítidos e em número de cinco.

Dentes - Dispostos em série única em ambas as maxilas e implantados não muito firme nos intermaxilares e dentário, apre- 
sentam a forma de garras e dispostos lado a lado com o aspecto dos dentes de um pente. O tamanho é aproximadamente o mesmo para todos; observamos, ainda, em cada maxila, a ocorrência de dois caninos ligeiramente recurvados para trás, cujo tamanho dos inferiores é aproximadamente o dôbro dos superiores. Os dentes são hialinos e suas extremidades coradas por um amarelo-citrino. Vômer e palato edêntulos.

Contamos um total de 26 dentes superiores e 20 inferiores, inclusive os caninos.

BRÂNQUIAS - Com as lamellae de aspecto plumiforme e bem individualizadas, rastros pouco numerosos e de forma cilindro-cônica suavemente recurvados látero-lateralmente bem espaçados.

NADAdEIRAS - Desenvolvidas e apresentando coloração semelhante à do restante do corpo, com exceção da caudal, onde há incidência menos intensa do pigmento negro.

A nadadeira dorsal tem o seu início na linha que passa pelo ângulo formado pelos ramos ascendente e descendente do préopercular; os seus raios duros indiferem dos flexíveis, apenas ocupam uma maior parte do dorso e são menos elevados que aquêles. Os raios duros aumentam de tamanho à medida que se distanciam da cabeça, ocorrendo o inverso com os outros. Esta nadadeira apresenta o seu último raio ligado pela membrana à base do primeiro raio acessório superior da caudal. Vamos, ainda, observar de curioso a ocorrência, no início da dorsal, de uma expansão da membrana que vai ultrapassar o primeiro raio, ficando como que uma bandeirola prêsa ao meio do bordo voltado para a frente do indivíduo (Fig. 5).

A anal tem seu início à altura do embasamento do $11 .^{\circ}$ raio dorsal; apresenta os raios duros indistintos dos moles e tem o seu primeiro raio duro modificado. O último raio desta nadadeira, à semelhança daquele da dorsal, une-se pela membrana ao primeiro raio acessório inferior da caudal. Seus raios aumentam de porte até o antepenúltimo, daí então decrescem.

As nadadeiras peitorais com o contôrno semi-elíptico possuem o embasamento na linha baixada pelo terceiro raio dorsal, chegando o bordo da membrana braquiostegal a tocá-lo suavemente.

As ventrais são toracojugulares e têm a sua base à mesma altura da das peitorais, sendo também tocadas pela membrana branquiostegal.

A nadadeira caudal apresenta os dez raios internos todos bifurcados. 
Linha lateral (Fig. 3) - Iniciada logo acima do término da fenda opercular, apresenta-se formada por poros que são ligados dois a dois por intermédio de um canalículo. A princípio ela é arqueada súpero-inferiormente até atingir a linha mediana longitudinal do indivíduo e seus poros são mais próximos uns dos outros, daí segue reta, com os poros bem mais espaçados, até a altura da base do último raio dorsal.

Diagnose DIFEREnCial - Após detido exame da literatura e do material existente em nossas coleções optamos pela criação de uma nova espécie, que denominamos Blennius paivai sp. nov., em virtude de nosso material divergir das descrições existentes pela sua morfologia externa que apresenta caracteres tais como a presença do prolongamento da membrana interradial à frente do primeiro raio dorsal, a prega dérmica tubular encimada por um tentáculo simples no primeiro par de narinas e o ligamento das nadadeiras dorsal e anal pelas respectivas membranas à base dos primeiros raios acessórios superior e inferior da caudal, guardando, porém, os caracteres básicos que a incluem no gênero Blennius Linnaeus, 1758.

MATERIAL ESTUDADo - M.N.I. 9119, holótipo macho - Rio Nóbrega (abaixo do local do cêrco experimental, ao nível da maré média) - Cananéia - São Paulo - Brasil / Dr. V. Sadowsky col. 13-4-1955 / Obs.: o exemplar tornou-se mais escuro depois de morto.

O exemplar encontra-se marcado com contas vermelhas no armário de tipos da Seção de Ictiologia do Museu Nacional.

\section{S U M M A R Y}

In the present paper the author describes Blennius paivai n. sp., from Cananéia, São Paulo, Brazil, based upon external morphological characters, chiefly dorsal fin and nares, besides giving figures and a table of measurings. 
TABELA

Blennius paivai sp. nov. (em $\mathrm{mm}$ )

Número

9.119

Comprimento:

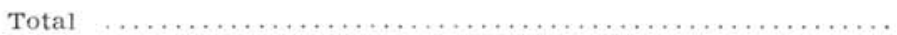

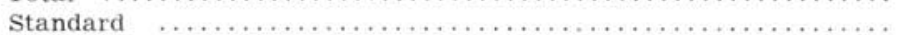

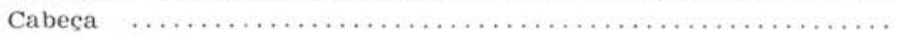

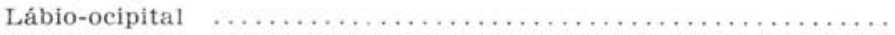

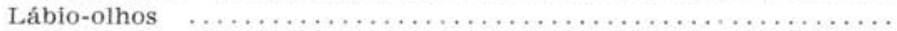

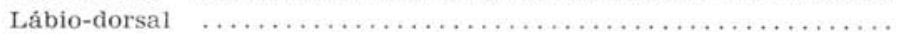

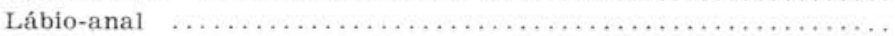

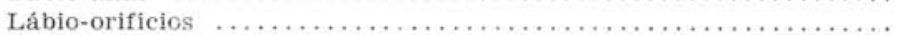

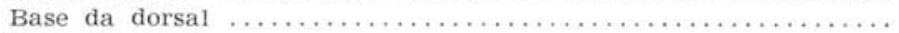

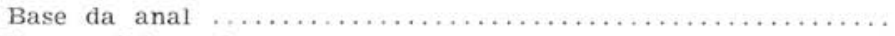

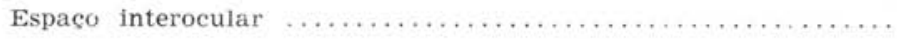

\section{Altura:}

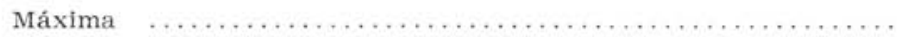

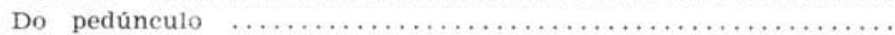

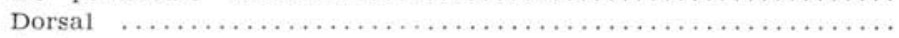

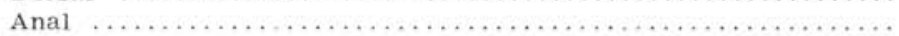

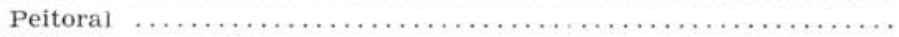

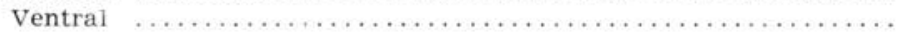

\section{Largura:}

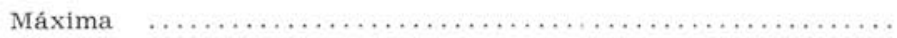

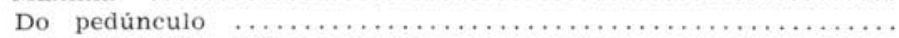

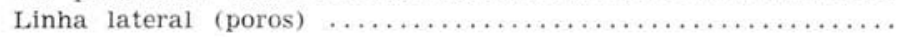

Raios:

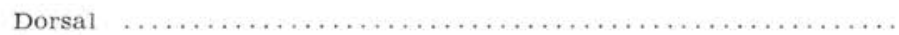

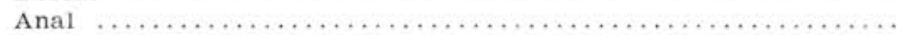

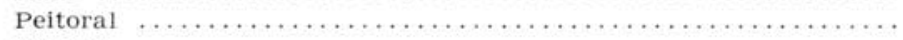

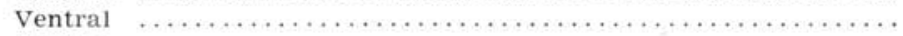

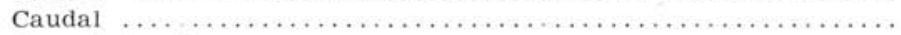

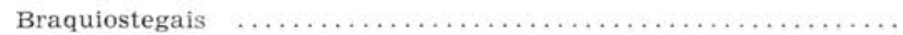

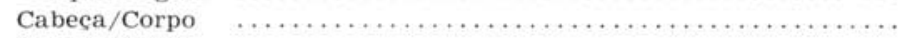

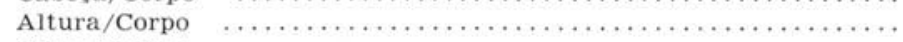

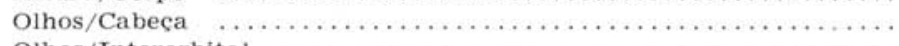

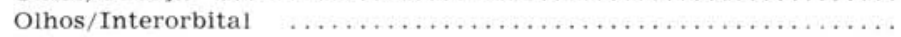

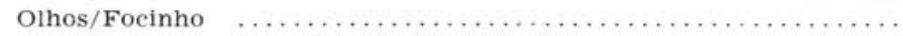

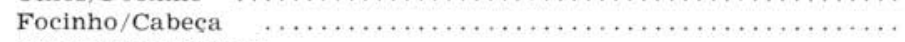

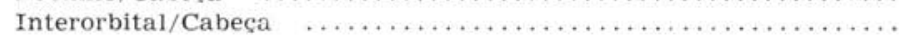


ESTA M P A I

Blennius paivai sp. nov.

Fig. 1 - Fotografia do aspecto geral.

Fig. 2 - Fotografia mostrando detalhes da cabeça

Exemplar M.N.I. 9119, comprimento total igual a $48,5 \mathrm{~mm}$ (Foto Moacyr Leão) 
Pinto, S. Y. - Um novo Blennidae...

ESTAMPA I
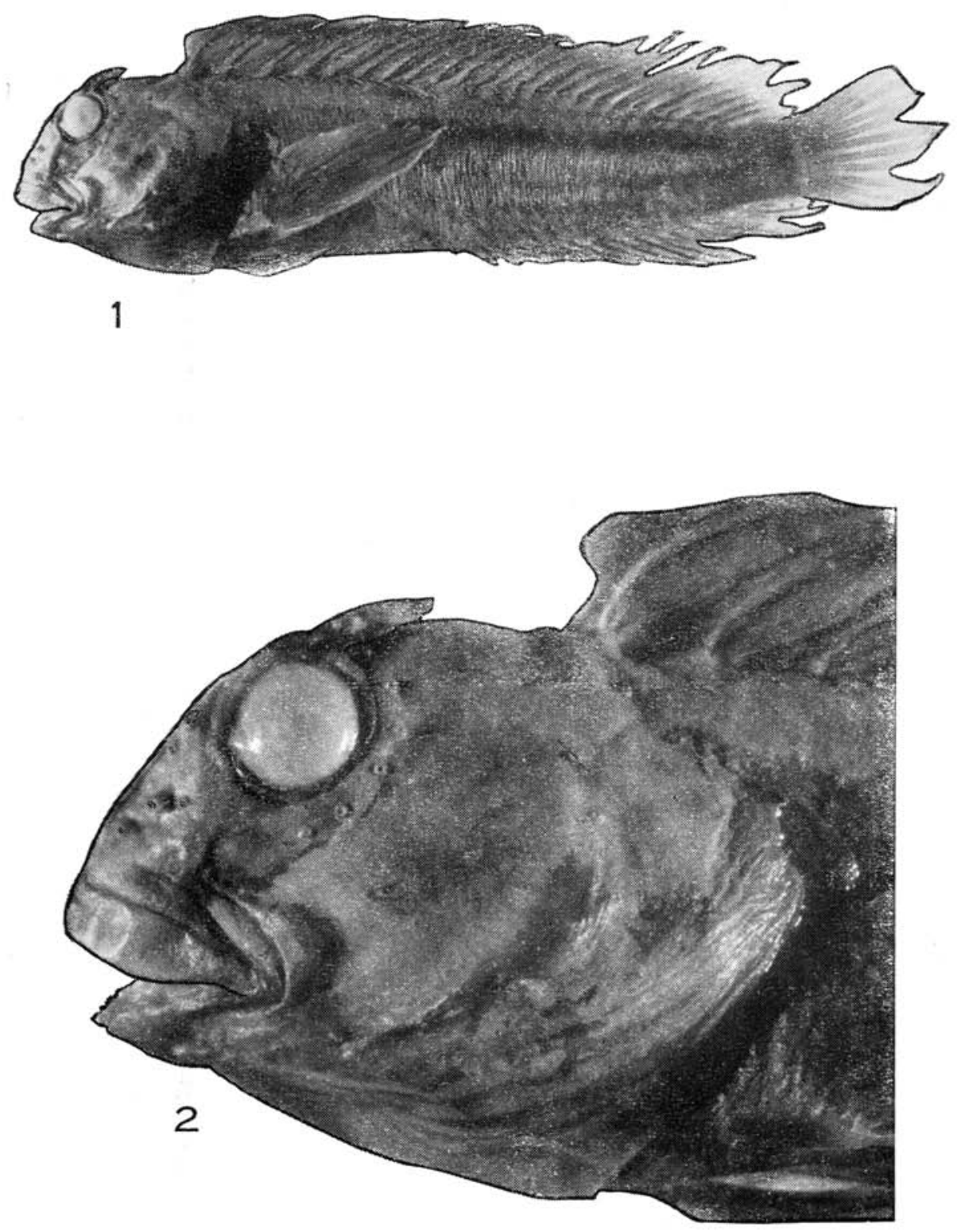
E T T A P A II

Blennius paivai sp. nov.

Fig. 3 - Distribuição dos poros da cabeça e da linha lateral.

Fig. 4 - Distribuição dos poros da porção superior da cabeça (vista de tôpo). 

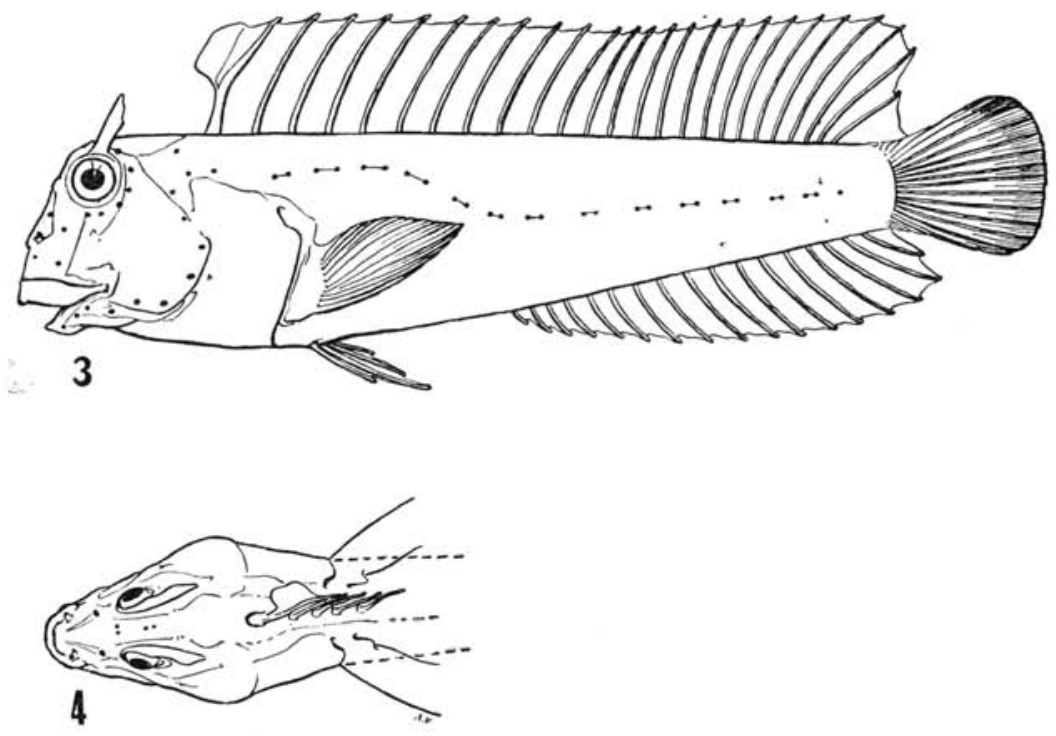
EST A M P III

Blennius paivai sp. nov.

Fig. 5 - Detalhe do perfii dorsal mostrando os três primeiros raios da nadadeira dorsal e o prolongamento anterior da membrana interradial

Fig. 6 - Detalhe do cirro supra-orbital (vista lateral externa).

Fig. 7 - Detalhe do cirro supra-orbital (vista lateral interna). 

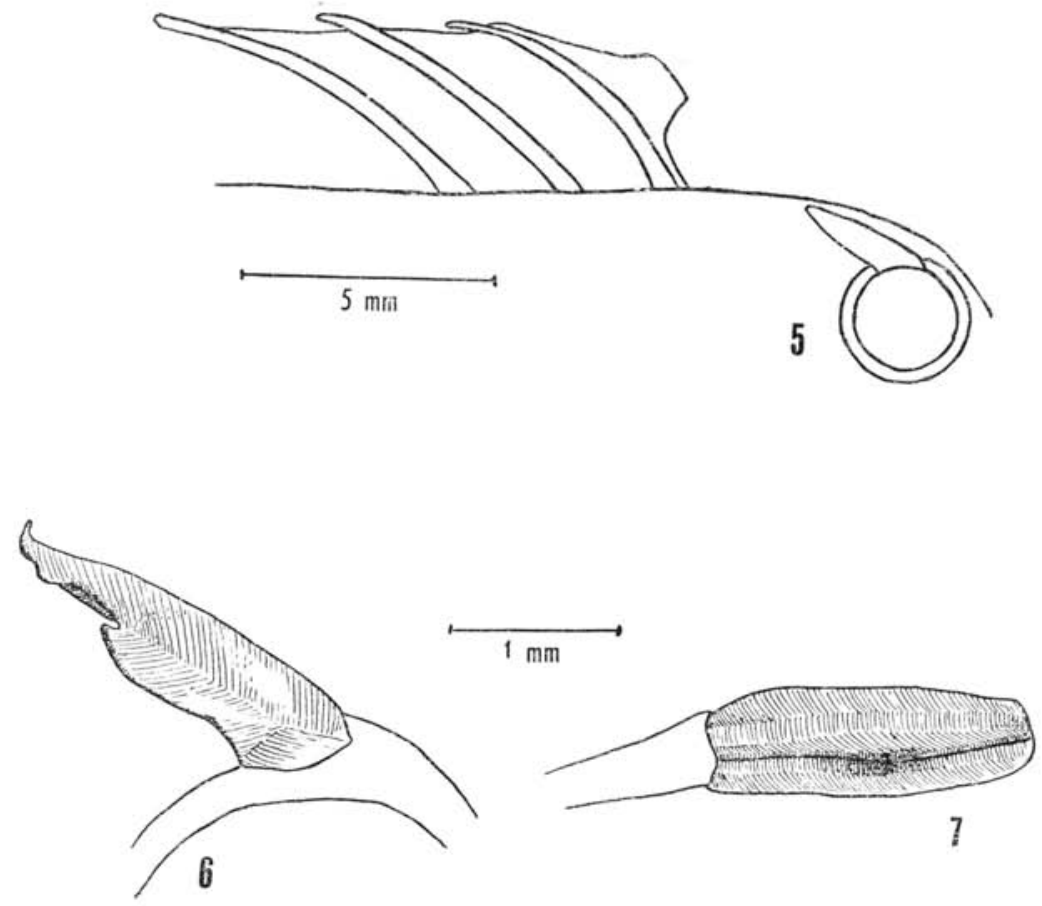